\title{
Climate change policy and its effect on market power in the gas market
}

\author{
David Newbery \\ Faculty of Economics, Cambridge \\ 10 November 2005
}

\begin{abstract}
The European Emissions Trading Scheme (ETS) limits $\mathrm{CO}_{2}$ emissions from covered sectors, especially electricity until December 2007, after which a new set of Allowances will be issued. The paper demonstrates that the impact of controlling the quantity rather than the price of carbon is to reduce the elasticity of demand for gas, amplifying the market power of gas suppliers, and also amplifying the impact of gas price increases on the price of electricity. A rough estimate using just British data suggests that this could increase gas market power by $50 \%$.
\end{abstract}

\section{Key words}

Climate change, emissions trading, market power, gas, quotas vs taxes

\section{JEL classification}

Q54, Q58, L94 


\title{
Climate change policy and its effect on market power in the gas market
}

\author{
David Newbery \\ Faculty of Economics, Cambridge \\ 14 November 2005
}

\section{Introduction}

The European Union has agreed the European Emissions Trading Scheme (ETS) as its principle means of reducing emissions of the main greenhouse gas, carbon dioxide, $\mathrm{CO}_{2}$. Each year from 2005 until the end of 2007 each country allocates at least $95 \%$ of its overall allowances to eligible firms, who are then free to trade them within the EU. The resulting price of an EU Emission Allowance (EUA) for 1 tonne of $\mathrm{CO}_{2}$ is determined by EU-wide demand and supply of EUAs. At the end of each calendar year covered industries, of which the largest is the electricity supply industry (ESI), must deliver EUAs equal in total to their recorded emissions in that year. EUAs can be held until the end of 2007, at which point a new scheme starts and the old EUAs become worthless.

EUA price

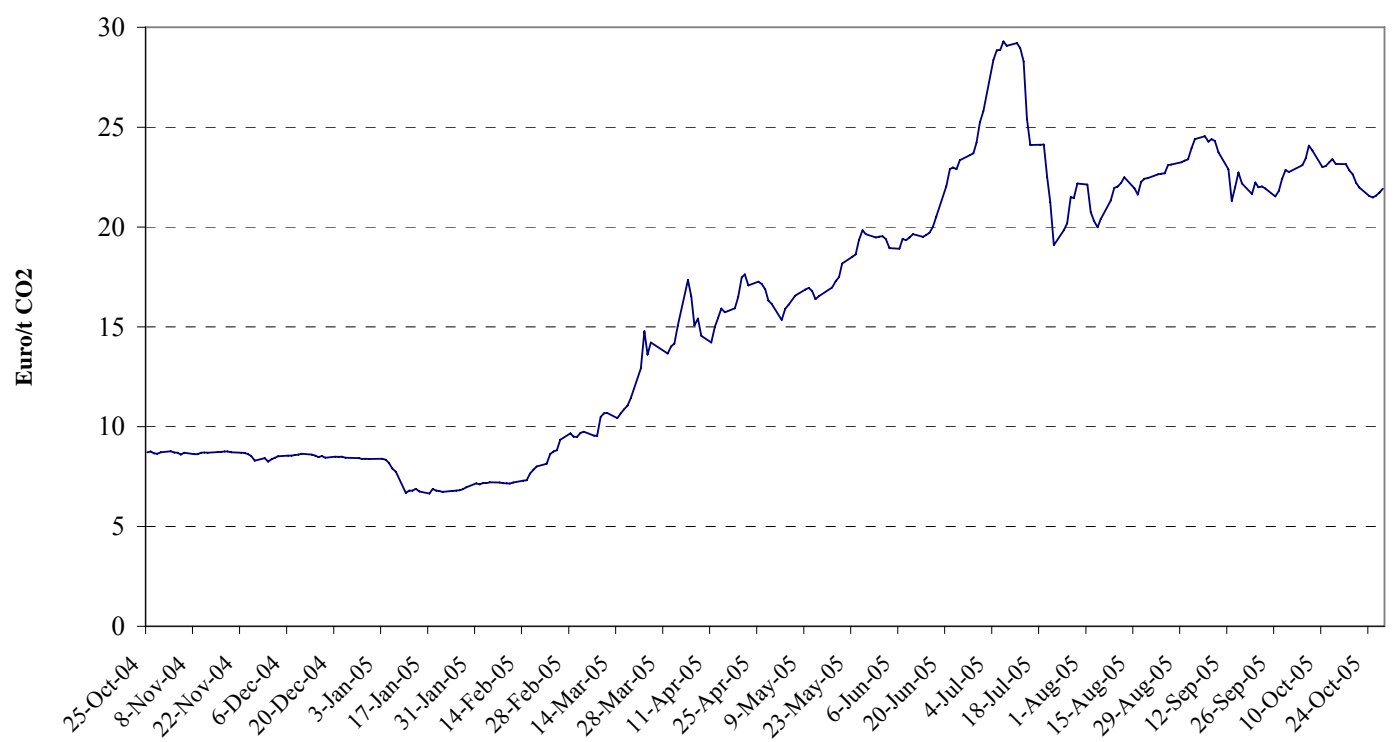

Figure 1 The EU price of $\mathrm{CO}_{2}$ valid for 2005-2007 (Source: EEX carbon index)

The market for EUAs has been volatile, as figure 1 shows. Moreover, the price of EUAs can be expected to feed through to the wholesale price of electricity in a competitive market, although where final prices are regulated, the price could be held down to offset the windfall profits earned on the allocated EUAs. Some evidence that the EUA price does indeed feed through to the wholesale price is provided by figure 2, which shows the spark spread in various markets and the cost of the $\mathrm{CO}_{2}$ emitted per MWh of electricity produced in a combined cycle gas turbine (CCGT) of 50\% efficiency. (The spark spread is the base-load price of electricity for the month ahead less the cost of the gas needed at $50 \%$ efficiency to 
generate that electricity, and is a measure of the gross profit needed to cover fixed and capital costs of generation).

\section{Spark spread month ahead $50 \%$ efficiency}

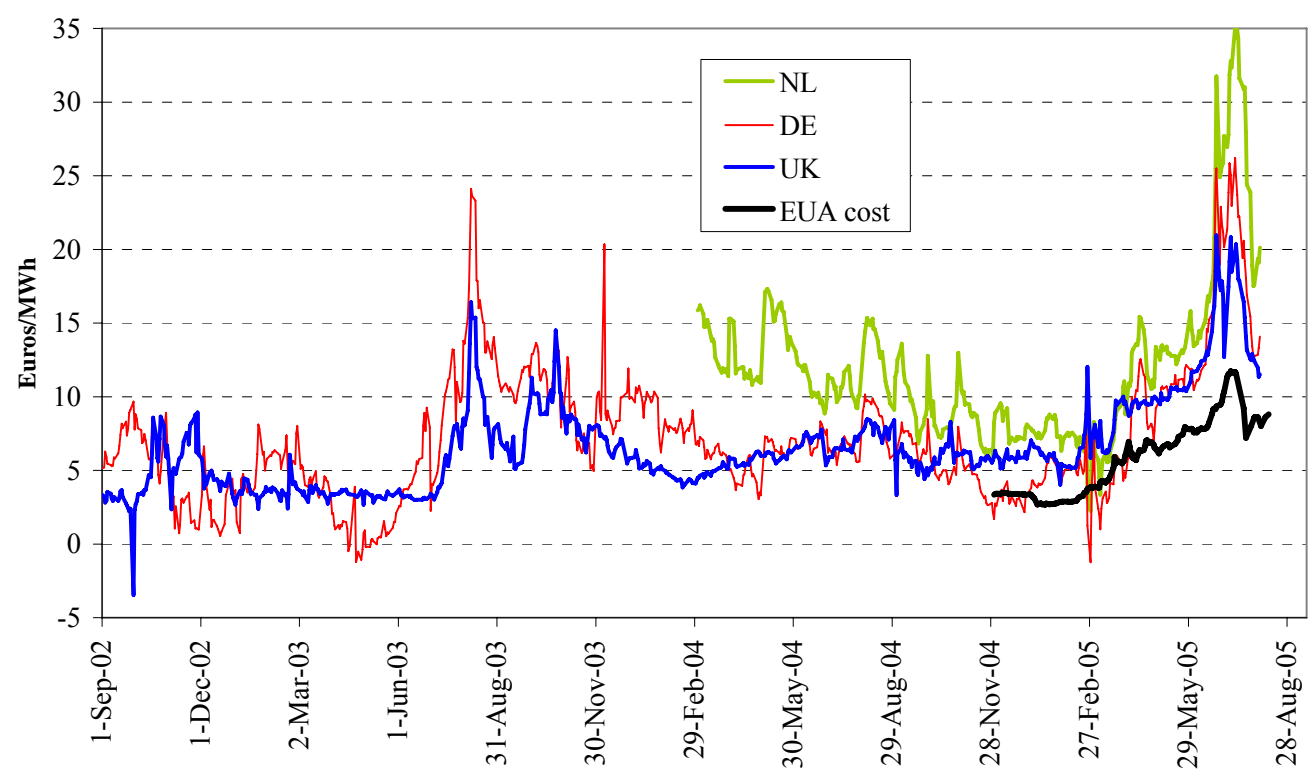

Figure 2 Spark spread and carbon cost in various EU markets (Source Platts)

The striking point that figure 2 hints at is that the price of electricity has risen dramatically in EU countries since the start of emissions trading. Between December 2004 and March 2005 weekly average European base-load prices rose more than doubled from about $35 € / \mathrm{MWh}$ to over $70 € / \mathrm{MWh}$, prompting a spate of complaints to the European Commission, who in response announced a sector inquiry into gas and electricity in June 2005 (European Commission, 2005).

A considerable part of the price rise could be attributed to a sharp increase in the price of gas, which increasingly sets the peak price in many EU countries. Year-ahead peak prices in Britain rose from about $50 € / \mathrm{MWh}$ in December 2004 to over $90 € / \mathrm{MWh}$ by July 2005 (Platts). However, the European Commission was sceptical that the price increase could be attributed to the normal functioning of competitive fuel markets and noted that network operators favoured their affiliates, that there was little transparency about available capacity and that access charges to gas networks did not appear to reflect costs. This raises two questions - how much of the electricity price rise was caused by the extra (opportunity) cost of $\mathrm{CO}_{2}$, and to what extent did the presence of the ETS aggravate the effect of market power in gas markets?

The impact on wholesale prices of the obligation to hold EUAs equal to the emissions from 1 January 2005 is shown by subtracting their opportunity cost from the spark spread in figure 3. The visual interpretation is that after an initial period of adjustment the gross profit margin has returned to where it had been, suggesting that most if not all of the EUA opportunity cost has been passed through into the wholesale price. 


\section{Spark spread net of EUA}

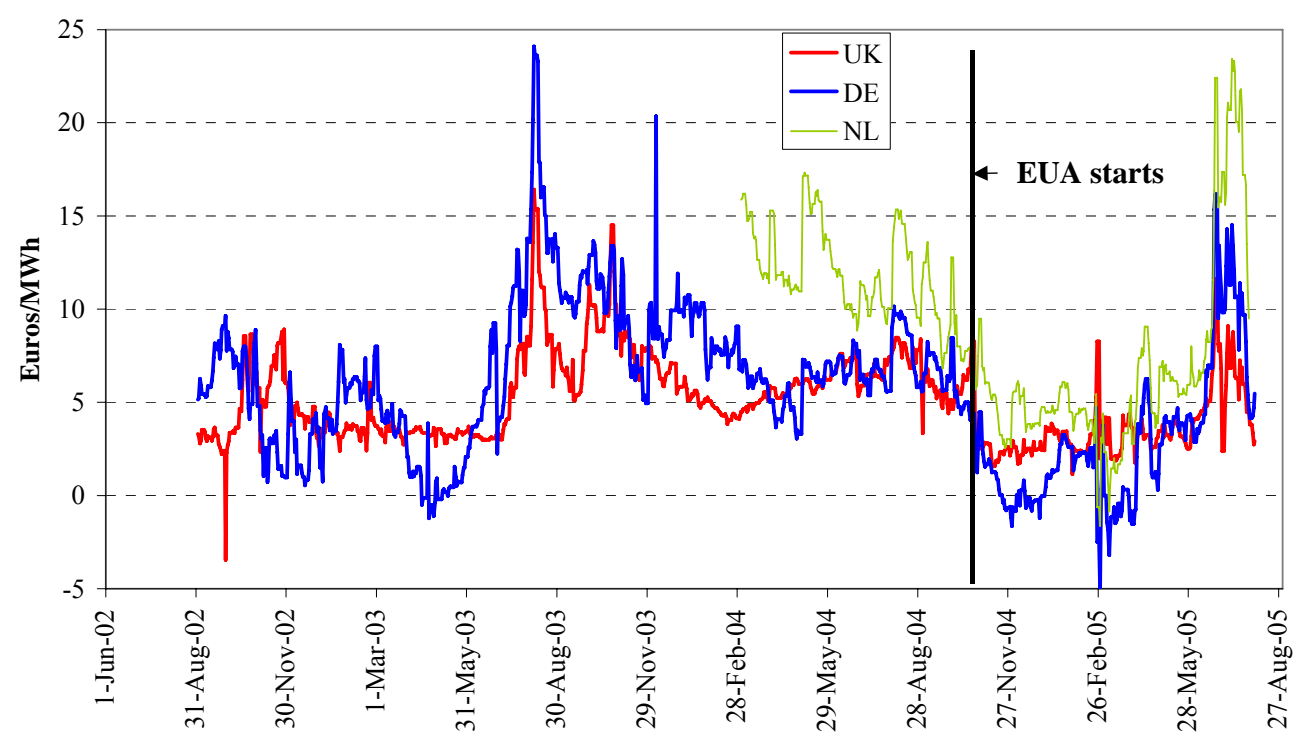

Figure 3 Gross profit of CCGT after paying for fuel and carbon (Source: Platts)

The price of EUAs is determined by supply and demand, and both depend on the extent to which the ESI can substitute less carbon-intensive fuels like gas for more carbonintensive fuels like coal though changes in the merit order. As the price of carbon increases, so gas becomes more attractive relative to coal and gas demand will increase, reducing the need for EUAs. More to the present point, as the price of gas increases, the value of EUAs increases, as the demand from coal-fired generation will increase demand for EUAs. While the international market for coal is reasonably competitive, the same is not true for gas, particularly in Europe, which is heavily dependent on importing Russian gas from the monopoly supplier, Gazprom. In addition, gas producers and suppliers in the EU have more market power than the suppliers of other fuels, and are frequently vertically integrated into electricity generation. There are therefore grounds for concern that the particular way climate change policy works in the EU through pricing a fixed supply of EUAs may amplify the existing market power in the gas market. This paper argues that such concerns should be taken seriously, and that these provide additional good reasons to move away from a quantity-determined climate policy to a price-based approach.

\section{A simple model of pricing EUAs}

To gain some insight into possible mechanisms, consider a very simple model in which the price of EUAs is dominated by supply and demand from the electricity supply industry, in the following way. Suppose that the prices of coal and gas are set on world markets and that the cost of coal is $c\left(€ / \mathrm{MWh}\right.$ of fuel) and of gas is $g$. The heat rate for fuel $f(f=c, g)$ is $h_{f}$ (MWh of fuel per MWh of electricity generated, or MWhe) so that the variable fuel cost (per MWh) is 
$h_{f} f € / M W h .{ }^{1}$ The fuel prices are initially such that the variable generation cost using coal is less than gas: $c h_{c}<g h_{g}$. Emissions (tonnes $\mathrm{CO}_{2}$ per MWh of energy content of fuel) $f$ is $e_{f}$, so emissions per MWhe of electricity generated will be $h_{f} e_{f}$. If the price of EUAs is $s € / t$, the variable cost, including the opportunity cost of the EUAs, will be $v_{f}=h_{f}\left(f+s e_{f}\right) € / \mathrm{MWhe}$. For the moment consider periods of the year in which there is enough gas and coal capacity to drive the wholesale price down to the variable cost of generation, but not enough coal capacity alone to meet demand then. If in such periods the price of electricity is $p$ and both technologies are required to meet demand, then the price of EUAs, $s$, and of electricity, $p$, must be such that

$$
p=h_{c}\left(c+e_{c} s\right)=h_{g}\left(g+e_{g} s\right) .
$$

or

$$
s=\frac{h_{g} g-h_{c} c}{h_{c} e_{c}-h_{g} e_{g}} .
$$

It follows that the price of electricity is

$$
p=\frac{h_{g} h_{c}\left(e_{c} g-e_{g} c\right)}{h_{c} e_{c}-h_{g} e_{g}} .
$$

and that the impact of gas prices on electricity prices is amplified, as

$$
\frac{d p}{d g}=\frac{h_{g} h_{c} e_{c}}{h_{c} e_{c}-h_{g} e_{g}}=h_{g}\left(\frac{1}{1-h_{g} e_{g} / h_{c} e_{c}}\right)>h_{g} .
$$

The partial effect of gas prices on electricity prices holding the price of EUAs constant is just $h_{g}$ so the effect of the feedback through the market for EUAs is given by the bracketed term, which magnifies the effect. To put some numbers on this suppose that $h_{g}$ is $2, h_{c}$ is $2.65, e_{c}=0.34$ tonnes $\mathrm{CO}_{2} / \mathrm{MWh}$ and $e_{g}=0.2 \mathrm{tCO}_{2} / \mathrm{MWh}$, then the multiplication factor will be 1.8 compared with a market in which the price of gas does not affect the price of EUAs. Interestingly, if coal becomes more efficient relative to gas the multiplier increases. Thus if $h_{c}$ were to fall to 2.5 the multiplier would become 1.9 .

This has interesting implications for the profits of generation companies. Suppose that their baseline output is $Q$ and they are allocated $h_{a} e_{a} Q$ EUAs, where $h_{a} e_{a}$ is an average emission factor per MWhe corrected by the amount of coverage (e.g. 95\%). The profit of the company if it sells $q$ units of electricity is

$$
\Pi=p q+s h_{a} e_{a} Q-h_{g}\left(g+s e_{g}\right) \alpha q-h_{c}\left(c+s e_{c}\right)(1-\alpha) q=s h_{a} e_{a} Q
$$

\footnotetext{
1 As defined, the heat rate is the inverse of the thermal efficiency, so for a CCGT of $50 \%$ efficiency the heat rate would be 2 .
} 
during those periods when the arbitrage equation (1) holds (and assuming no inframarginal coal or gas plants) (where $\alpha$ is the share of generation from gas during this period). Again from the price equation (2) for EUAs

$$
\frac{d \Pi}{d g}=\frac{e_{a} h_{g} Q}{h_{c} e_{c}-h_{g} e_{g}},
$$

so profits rise with the price of gas. This might give generating companies owned by gas suppliers (e.g. Gas Natural in Spain) an extra incentive to raise the price of gas (although an individual EU gas company might not have as much to gain as a major player like Gazprom). Again, to put some numbers on this, suppose that the baseline allocation is $95 \%$ and that the initial share of coal is $80 \%$, then $h_{a} e_{a}=0.722 \mathrm{tCO}_{2} / \mathrm{MWhe}$ and the multiplier of $Q$ in (6) is 1.6 .

Another way to examine the incentives to raise gas prices is to examine the demand for gas by the ESI as a function of the EUA price, $s$. In this overly simple model, at least during hours when there is excess capacity and variable cost pricing, coal and gas plants are perfect substitutes, with the price of EUAs set by the coal and gas prices according to (2). Equilibrium in the market for EUAs will thus depend on the supply of EUAs to the ESI, as in figure 4.

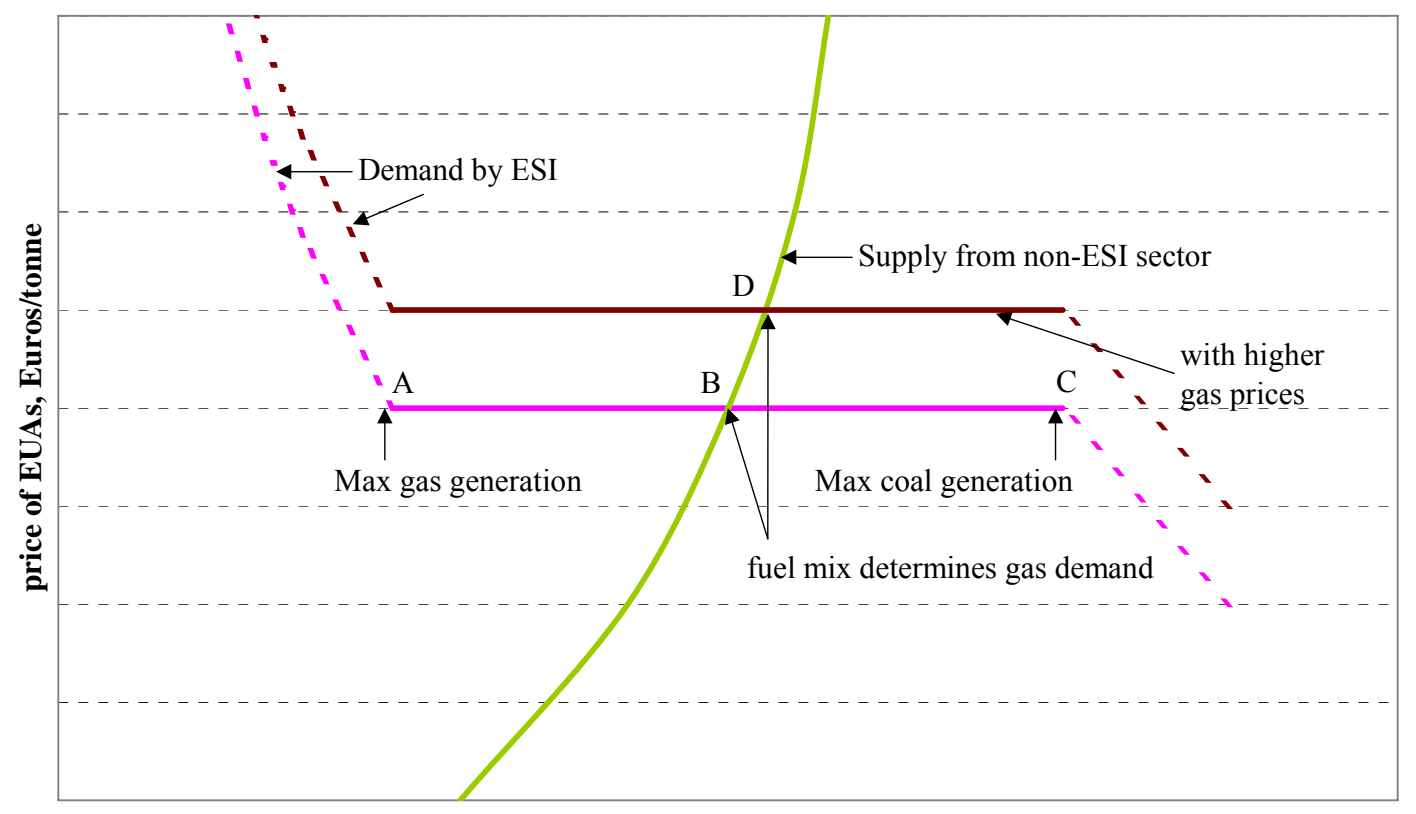

EUAs tonnes CO2

Figure 4 Supply and demand of EUAs in the electricity supply industry

The flat section of the demand for EUAs by the ESI, ABC, shows the range of combinations of coal and gas-fired plant that is capable of meeting demand during these hours, with low emissions requiring all CCGTs to run, at $\mathrm{A}$, and point $\mathrm{C}$ corresponding to the minimum gas use and maximum coal use. The actual demand for gas will be set by the intersection of the supply of EUAs from the rest of the economy at point B.

From (2), $d s / d g>0$, so if the price of gas increases, the whole demand schedule moves up, as in figure 4 , and the equilibrium shifts from B to D, which reduces the demand for gas as 
coal substitutes for gas (point D is closer to the maximum coal end of the horizontal part of the schedule. It is not immediately clear whether this indirect effect on the demand for gas makes the demand for gas less elastic than without the ETS, and hence amplifies the market power of gas producers, or not. To investigate that we need a more articulated model of the ESI.

\section{A more realistic model}

The simple model has a number of obvious drawbacks, in that it only considers periods of excess capacity and pricing at variable cost. While it gives a very direct link between the price of electricity and the prices of the fuels and EUAs, it does not provide a very helpful view of the demand for gas, and it only applies to part of the year. As the carbon price is determined by annual demand and supply it is important to extend the model to cover with varying levels of demand, and in so doing it is possible to develop a more realistic model of the demand for gas, which is our central concern.

To keep matters as simple as possible, assume that the price of carbon has little effect on the demand for electricity (compared to the demand for carbon), and that there are two technologies, gas and coal. ${ }^{2}$ Assume that all gas-fired plant is equally efficient but limited in capacity, measured by $K_{g} \mathrm{MW}$, so the variable cost of gas-fired plant is constant. Coal plants, in contrast, vary in efficiency, and the heat rate of the marginal plant increases with supply. Put another way, older less efficient coal plant is placed lower down the merit order and is only called after more efficient plant. The unsubscripted heat rate now refers to coal and is a function of its position in the merit order, with $h(K)$ the heat rate of the marginal coal plant of the most efficient $K \mathrm{MW}$ of coal plant, $K<K_{c}$, the total coal capacity. The simplest such model would have $h(K)=h_{0}+\alpha K$, (where $\alpha$ has dimensions $\mathrm{MW}^{-1}$ ) giving a linear increasing marginal cost schedule.

The merit order will now depend on the prices of coal, gas and EUAs. The variable (or marginal) cost of CCGT will be, as before, $v_{g}=h_{g}\left(g+s e_{g}\right)$. The marginal cost of coalfired plant is a function of $K: v(K)=h(K)\left(c+s e_{c}\right)$, which will be linear if the heat rate is linear: $v(K)=\left(h_{0}+\alpha K\right)\left(c+s e_{c}\right)$. The interesting case has some coal plant cheaper than gas, but older plant more expensive, or $h_{0}\left(c+s e_{c}\right)<h_{g}\left(g+s e_{g}\right)<\left(h_{0}+\alpha K^{*}\right)\left(c+s e_{c}\right)$, where if $D^{*}$ is peak demand, $K^{*}=D^{*}-K_{g}$. (Other cases are discussed in the Appendix.) Suppose the load duration curve is given by $D(t)=b+\mu(1-t)$, where $t$ is the fraction of the year that demand is higher than $D(t) \mathrm{MW}$ and both $b$ and $\mu$ are measured in MW, as shown in figure 5. Given the capacity of CCGT, $D^{*}=D(0)=b+\mu=K^{*}+K_{g}$ (so $K^{*}=b+\mu-K_{g}$ ).

\footnotetext{
2 This is not restrictive, given that the emissions per unit of electricity produced is increasing for "coal" units, so oil-fired plants can also be considered with a suitable reinterpretation of the heat rates.
} 


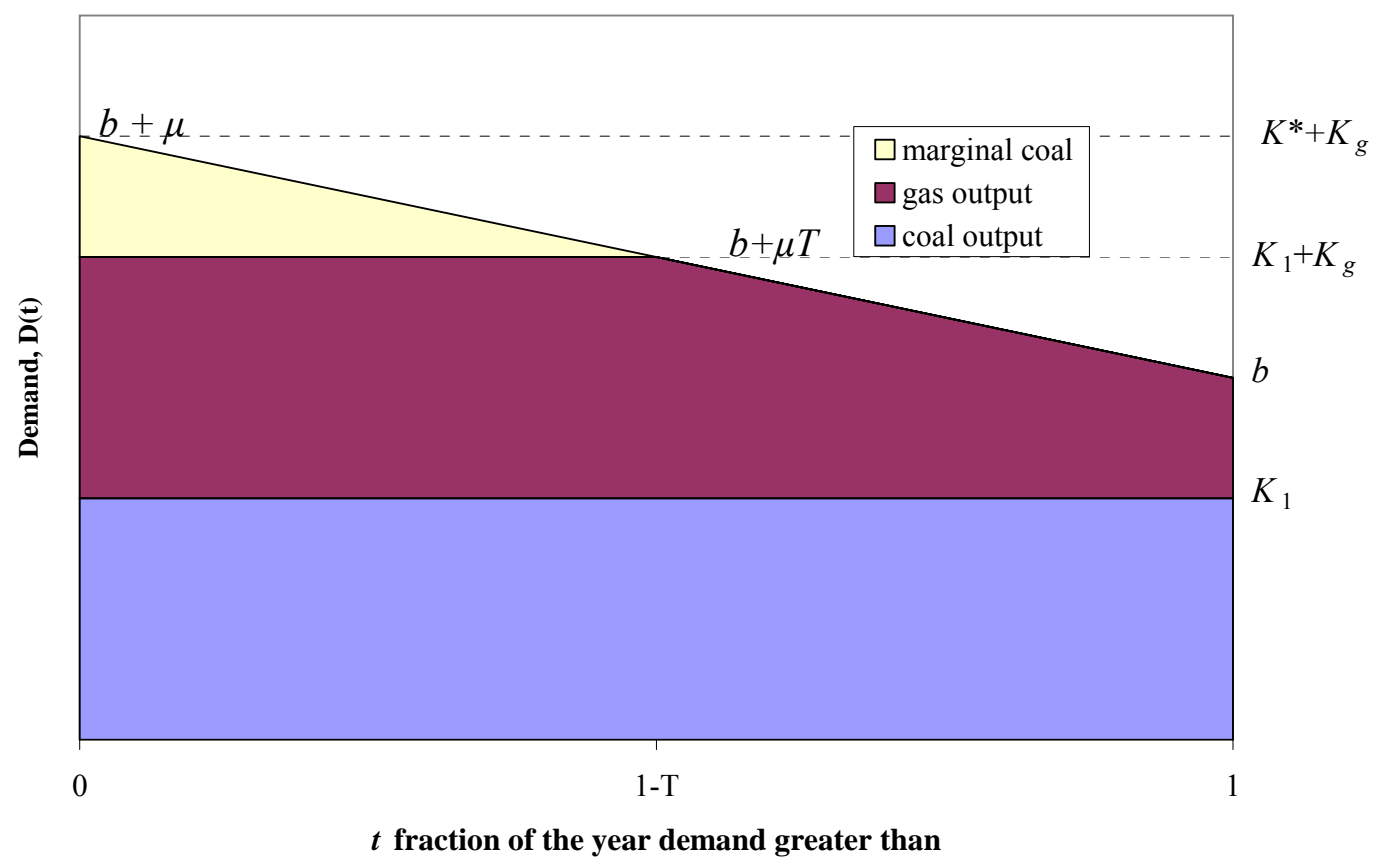

Figure 5 Load duration curve and shares of generation from each fuel

The merit order determines how many hours each plant runs and therefore generates and emits. Suppose that the lowest load factor CCGT runs a fraction $T$ of the year, then one possible configuration of the merit order has $K_{1}$ units of coal plant running on base-load, followed by $b-K_{1}$ units of CCGT running base-load and the remaining $\mu T$ MW of CCGTs running mid-merit, with the $\mu(1-T)$ units of higher cost coal supplying the peak, as in figure 5 . The value of $K_{1}$ is such that the marginal costs are there equal, so

$$
\left(h_{0}+\alpha K_{1}\right)\left(c+s e_{c}\right)=h_{g}\left(g+s e_{g}\right)
$$

or

$$
K_{1}=\frac{h_{g}\left(g+s e_{g}\right)}{\alpha\left(c+s e_{c}\right)}-\frac{h_{0}}{\alpha}
$$

The value of $T$ then solves $b+\mu T=K_{1}+K_{g}$, or $T=\left(K_{1}+K_{g}-b\right) / \mu$. The total generation of gas-fired electricity is found by geometry from figure 1 to be the base-load and mid merit outputs: $Q_{g}=b-K_{1}+1 / 2 \mu T(2-T) \mathrm{MW}$ years. Emissions from gas-fired plant are $E_{g}$ $=8760 h_{g} e_{g} Q_{g}$. Total coal-fired generation is $Q_{c}=K_{1}+1 / 2 \mu(1-T)^{2} \mathrm{MW}$ years, but emissions will vary with the plant dispatched, and must be found by integration:

$$
E_{c}=8760 e_{c}\left(\int_{0}^{K_{1}} h(q) d q+\frac{1}{\mu} \int_{K_{1}}^{K^{*}}\left(K^{*}-q\right) h(q) d q\right)=E_{c}\left(K_{1}\right) .
$$

As the price of EUAs increases, so the volume of base-load coal plant, $K_{1}$, decreases as gas is favoured in the merit order, increasing its share of total generation and thus displacing more carbon-intensive coal. Total emissions, $E=E_{g}+E_{c}$, are therefore a 
decreasing function of the EUA price, $s$. If the supply schedule of EUAs from other sectors supplied to the market is increasing in $s$, the equilibrium value of $s$ will be determined by the intersection of supply and demand. ${ }^{3}$ If the price of coal is assumed constant, then the price of EUAs will depend on the price of gas.

\section{Exercising market power in the gas market}

The demand for gas from the ESI will depend on its price, the price of coal (which is assumed constant and independent of demand), and the price of EUAs, which is in turn determined by the prices of fuels. The main question to be addressed is whether the particular form of the ETS amplifies, mitigates, or is neutral to the exercise of market power by gas suppliers. To simplify, suppose the supply of EUAs to the ESI, $S(s)$, depends on the price of EUAs only and not on the price of gas. (This assumption can be relaxed without changing the direction of the results, but at the cost of greater complexity in modelling the EUA market.)

The ESI demand for gas is $G=8760 h_{g} Q_{g}=\theta Q_{g}$, which is a function of $K_{1}$, so $d G / d g=\theta\left(d Q_{g} / d K_{1}\right) .\left(d K_{1} / d g\right)$. For the merit order shown in Figure $5, d Q_{g} / d K_{1}=-T$. The crucial derivative is therefore $d K_{1} / d g$, which from (7) is

$$
\frac{d K_{1}}{d g}=\frac{\partial K_{1}}{\partial g}+\frac{\partial K_{1}}{\partial s} \frac{d s}{d g}
$$

The value of $d s / d g$ can be found by examining the intersection of the demand for and supply of EUAs to the ESI. The demand for EUAs by the ESI is a function of the price of gas and of EUAs, $E\left\{K_{1}(g, s)\right\}$, whereas the supply is just a function of the EUA price, $S(s)$. Equilibrium in the market for EUAs is found from $S(s)=E\left\{K_{1}(g, s)\right\}$. Differentiate this totally with respect to the gas price, $g$ :

$$
\frac{\partial S}{\partial s} \frac{d s}{d g}=\frac{\partial E}{\partial K_{1}}\left(\frac{\partial K_{1}}{\partial g}+\frac{\partial K_{1}}{\partial s} \frac{d s}{d g}\right)
$$

or, rearranging and simplifying

$$
\frac{d s}{d g}=\frac{\frac{\partial K_{1}}{\partial g} / \frac{\partial K_{1}}{\partial s}}{\frac{\partial S}{\partial s} /\left(\frac{\partial E}{\partial K_{1}} \frac{\partial K_{1}}{\partial s}\right)-1}
$$

This can now be inserted into equation (9) to give

\footnotetext{
3 The qualification is that EUAs can be used any time between 1 Jan 2005 and 31 Dec 2007 so the demand and supply should be thought of as 3-year totals selling in theory at a single price.
} 


$$
\frac{d K_{1}}{d g}=\frac{\partial K_{1}}{\partial g}\left(1-\frac{1}{1-\frac{\partial S}{\partial s} /\left(\frac{\partial E}{\partial K_{1}} \frac{\partial K_{1}}{\partial s}\right)}\right)
$$

The various terms can now be derived from (8) as follows:

$$
\frac{\partial E_{c}}{\partial K_{1}}=8760 e_{c}\left(h\left(K_{1}\right)-\frac{1}{\mu}\left(K^{*}-K_{1}\right) h\left(K_{1}\right)\right)=8760 e_{c} h\left(K_{1}\right) T
$$

which makes use of the relation $K^{*}-K_{1}=\mu(1-T)$. Given the equation for $E_{g}=8760 h_{g} e_{g} Q_{g}$, the full derivative is:

$$
\frac{\partial E}{\partial K_{1}}=8760 T\left(e_{c} h\left(K_{1}\right)-e_{g} h_{g}\right)>0
$$

The term $\partial K_{1} / \partial s$ is found from (7) to be

$$
\frac{\partial K_{1}}{\partial s}=-\frac{h_{g}\left(e_{c} g-e_{g} c\right)}{\alpha\left(c+s_{c}\right)^{2}}<0
$$

If the elasticity of supply of EUAs to the ESI is $\eta$, then $\partial S / \partial s=\eta E / s$, and all the necessary elements are now available to calculate the elasticity of ESI demand for gas with the ETS:

$$
\varepsilon^{*}=\frac{g}{G} \frac{d G}{d g}=\frac{-\theta T}{\theta Q_{g}} \frac{g d K_{1}}{d g}
$$

The elasticity without the ETS (or with the price of EUAs independent of the price of gas), $\varepsilon$, is found by replacing $d G / d g$ by $\partial G / \partial g$. The ratio of the elasticity with and without the ETS is then

$$
\frac{\varepsilon^{*}}{\varepsilon}=\left(\frac{\eta}{\eta+\phi}\right), \quad \phi \equiv\left(\frac{K_{l} \partial E}{E \partial K_{l}}\right)\left(\frac{-s \partial K_{I}}{K_{l} \partial s}\right) .
$$

For example, if we roughly calibrate this for Britain in 2005 with the parameters shown in table 1.

Table 1 Parameters for calibrating the model to Britain, 2005

gas heat rate

coal base heat rate

rate of change of $\mathrm{HR}$

$\mathrm{CO}_{2}$ per $\mathrm{MW}$ gas $h_{g} \quad 2$

$h_{0} \quad 2.5$

$\alpha \quad 0.025$ per GW

$e_{g} \quad 0.2$ tonnes/MWh 


$\begin{array}{llc}\mathrm{CO}_{2} \text { per MW coal } & e_{c} & 0.34 \text { tonnes/MWh } \\ \text { min demand } & b & 25 \mathrm{GW} \\ \text { Slope of load duration } & \mu & 30 \mathrm{GW} \\ \text { gas capacity } & K_{g} & 20 \mathrm{GW} \\ \text { coal capacity } & K_{c} & 40 \mathrm{GW} \\ \text { Price of gas } & g & 16 € / \mathrm{MWh} \\ \text { Price of coal } & c & 6 € / \mathrm{MWh} \\ \text { EUA price } & s & 20 € / \text { tonne } \mathrm{CO}_{2}\end{array}$

Given these values, $\varphi=0.55$. If the elasticity of EUA supply, $\eta$, is 0.1 then the elasticity of gas demand is reduced to two-thirds its unconstrained value, and the Lerner Index (the markup as a fraction of the price) will be increased by $50 \%$.

The effect of an increase in gas price on the demand for (and hence price of) EUAs is unambiguous. Higher gas prices move gas down the merit order (and up the load duration schedule in figure 5) and reduce gas-fired generation, increasing emissions and hence increasing the demand for EUAs, raising their price and magnifying the impact of the gas price rise on the price of electricity. Equation (14) shows that the effect of carbon trading is to reduce the elasticity of demand for gas, amplifiying the market power of the gas supplier.

\section{Policy implications}

The amplification of market power works through the impact on the price of EUAs, which, as gas prices rise and lead to coal substituting for gas, raise emissions and hence the price of EUAs, which in turn favours gas, offsetting the normal market demand response to an increase in the price of gas. As the EU gas market is thought to be less competitive than either the electricity or coal market, and as Gazprom clearly has some market power, it seems desirable to find ways of addressing climate change without exacerbating these other market failures, particularly where the result is not just a redistribution of income between gas companies and consumers within the EU (as well as extra deadweight losses) but also an increased transfer to gas producers outside the EU.

The obvious solution is to cut the link between the demand for EUAs and their price by fixing the price of the EUAs. This could be done either by the European Commission (or some body) being prepared to buy and sell any number of EUAs at the fixed price, or by replacing the ETS by a fixed carbon tax per tonne of carbon burned. The former is likely to be politically more attractive than the latter, and can be made cash positive or neutral to the EC by suitable reductions in the allocations of EUAs each year. A similar proposal termed the "safety valve" is discussed by Jacoby and Ellerman (2004)..

There are additional arguments for setting the price of carbon and allowing the market to determine emissions, rather than setting the quantity and allowing the market to determine the price, all deriving from the insights of Weitzman's seminal paper on prices vs. quantitites. Weitzman (1974) started a lengthy debate by observing that in the presence of uncertainty, permits are only superior to taxes if the marginal benefit schedule had more curvature than the marginal abatement schedule. This might be the case if marginal damage were low until some 
threshold level, at which point it suddenly increases. For most pollutants the marginal abatement cost schedule is fairly flat and low for modest abatement, but rises rapidly as a higher fraction of emissions is to be curtailed, arguing for taxes rather than quotas. The damage contributed by emissions today is effectively the same as those tomorrow, and so the marginal benefit of abatement is essentially flat at each moment, while the marginal cost of abatement rises rapidly beyond a certain point.

The scale of the hazard of global warming is very uncertain, as are the future costs of reducing carbon intensity. All these provide additional arguments for a carbon tax (or fixed price) rather than tradable permits. Hoel and Karp (2001) explore this question more carefully in a calibrated linear-quadratic dynamic model of global warming and confirm this claim robustly. Karp and Zhang (2004) extend the analysis, taking account of the stock nature of $\mathrm{CO}_{2}$ emissions and uncertainty about costs, but also taking account of asymmetric information about the costs of abatement and learning about the cost of global warming. Again they find that taxes are superior to quotas or tradable permits.

\section{Extensions}

The simple model gave a direct link between the electricity price and the price of gas and EUAs, as it only studied periods of excess capacity and variable cost pricing. The more realistic merit order model can derive the impact of gas prices on variable costs for each level of demand, but needs an extension to properly model the impact on electricity prices. A more complete model would also look at the recovery of fixed costs via the conditions (and cost) of entry and the required reserve margin, which will affect the wholesale price. During periods when the price is dominated by the variable cost (low price periods of excess supply, covering in figure 5 the lowest fraction $T$ of the year), the effect is straightforward:

$$
\frac{d v_{g}}{d g}=h_{g}\left(1+e_{g} \frac{d s}{d g}\right)
$$

The first term is the direct impact of gas prices on the variable cost, which should feed directly through to the wholesale price, but as in the first model the effect is magnified by the second term, which is positive. The same is true for the most expensive 1-T fraction of the year in figure 5, when coal is at the margin. There will be an additional term $e_{c} . d s / d g$ increasing the effect (which would otherwise be zero, as the same coal-plant would be at the margin in the top $1-T$ fraction of the year). ${ }^{4}$

The impact on wholesale prices will be made up of the impact on the variable cost and on the capacity charge. If CCGT were the preferred investment before and after the price change there should be no effect on the capacity cost and hence on the extra capacity charge in the wholesale price. If gas prices are so magnified by the ETS that coal becomes preferred, then capacity costs would be higher and the capacity charge might have to increase. Whether this is likely might depend on the response of gas suppliers. On the one hand, the demand for

${ }^{4}$ There is a small effect in some hours in that the margin $T$ will change with the change in gas and EUA prices. 
gas has been made less elastic by the ETS, allowing gas suppliers to raise prices more for a given reduction in gas, and so arguably making it less likely that gas supplies would fall so much as to require coal to displace gas for new investment. On the other hand, governments may feel that to counter the increased market power of gas suppliers, coal should be favoured by the system of allocating new EUAs. If the EUA price were capped that argument might be more effectively countered.

\section{Conclusions}

The ETS restricts total emissions of $\mathrm{CO}_{2}$ and determines their price (until 2007) by market trading. As a result the price is volatile (although trading between years reduces this volatility somewhat. This volatility is costly in a variety of ways, not least in making investment decisions more risky and therefore the cost of capital higher. There are powerful arguments for preferring a climate change policy that stabilises the price of EUAs (or greenhouse gases, GHGs, more generally), based on the stock nature of GHG emissions, and given uncertainties and ignorance about the nature of the costs of mitigation and of climate change. This paper has advanced an additional argument in favour of setting the price of EUAs rather than the quantity, in that $\mathrm{CO}_{2}$ quotas rather than taxes amplify the damaging effects of imperfect competition in the gas market.

It is well-known that tariffs and quotas are not equivalent in the presence of imperfect competition in domestic markets (Bhagwati, 1965), and that under certainty, tariffs are superior (in the strong sense that an optimal tariff would be better than the optimal quota). The reason is simple - a binding quota limits imports of competing products and makes the residual demand facing the home supplier less elastic than would be the case if imports were subject to a tariff. It is also well-known that demand is less elastic in the presence of rationing, even where the rationing applies to other markets than the one under study (Neary and Roberts, 1980). This in turn is an illustration of the Le Chatelier Principle that constraints reduce the elasticity of response, as noted by Samuelson (1947) and set out in standard textbooks (e.g Varian, 1984, p56). The same applies if the quantity of EUAs is fixed, as this reduces the elasticity of demand for gas and enhances the market power of those selling gas, including large foreign suppliers such as Gazprom.

The political advantages of the current ETS should not be underestimated, and these need to be retained when designing the next phase to start in 2008. The preferred solution would be to agree a price for GHGs, and for the European Commission to be willing to sell any demanded and not supplied by the market, or to intervene to buy back surplus EUAs. The allowances to be allocated free should be scaled back so that the risk of the EC having to buy back EUAs is reduced to very low levels. There may then be a good case for eliminating the discontinuity at the end of 2007 by extending the price-setting mechanism into the first period. As better information about EU GHG supply and demand, and about the costs and benefits of reducing GHG emissions, arrives, so the intervention price can be modified, although there are probably good arguments for issuing long-term contracts for differences on the prevailing price to provide greater certainty for low-carbon investments. 


\section{References}

Bhagwati, Jagdish, (1965) 'On the Equivalence of Tariffs and Quotas' in Trade, Growth, and Balance of Payments: Essays in Honor of Gottfried Haberler, editors: R.E. Baldwin et.al. Chicago.

European Commission (2005) The Week in Europe 17 June 2005 available at http://www.cec.org.uk/press/we/we05/pdf/we0523.pdf

Hoel, M. and L. Karp (2001) "Taxes and quotas for a stock pollutant with multiplicative uncertainty" Journal of Public Economics, 83, 91-114

H. D. Jacoby and A. D. Ellerman, The safety valve and climate policy, Energy Policy, 32 (4) 2004, 481-491

Karp, L. and J. Zhang (2004) "Regulation with anticipated learning about environmental damages", University of California, Berkeley

Neary, J.P and K.W.S. Roberts, (1980) 'The Theory of Household Behaviour under Rationing' European Economic Review. 13(1): 25-42

Newbery, D.M. (2005) 'Why tax energy? Towards a more rational policy', Energy Journal, 26 (3), 1-39

Platts reporting services, http://www.platts.com

Samuelson, P.A. (1947) Foundations of Economic Analysis, Camrbndge Mass: Harvard Varian, H.R. (1984) Microeconomic Analysis, New York: Norton

Weitzman, M.L. (1974) “Prices vs. Quantities”, Rev. Econ. Stud. 41 (4), 477-91 


\section{Appendix Other configurations of the merit order}

If the price of gas is low enough, then gas will run base-load before any coal. The condition for this is given by $K_{1}$ in (7) being zero or negative, or

$$
g<\frac{h_{0}\left(c+s e_{c}\right)}{h_{g}}-s e_{g}
$$

In this case, total gas-fired generation and total emissions from gas will be independent of the price of gas and the EUA price until condition (A1) is violated, in which case we return to the case discussed in the text. Over this initial range of (low) gas prices, the EUA price would not respond to the price of gas and hence the amplification effect discussed in the paper would initially be absent.

As the price of gas rises further, so will $K_{1}$ until it exceeds $b$ as shown in figure A1. This complicates the derivation of responses, as there are now two margins for gas, but it does not alter the conclusion, which appears remarkably robust.

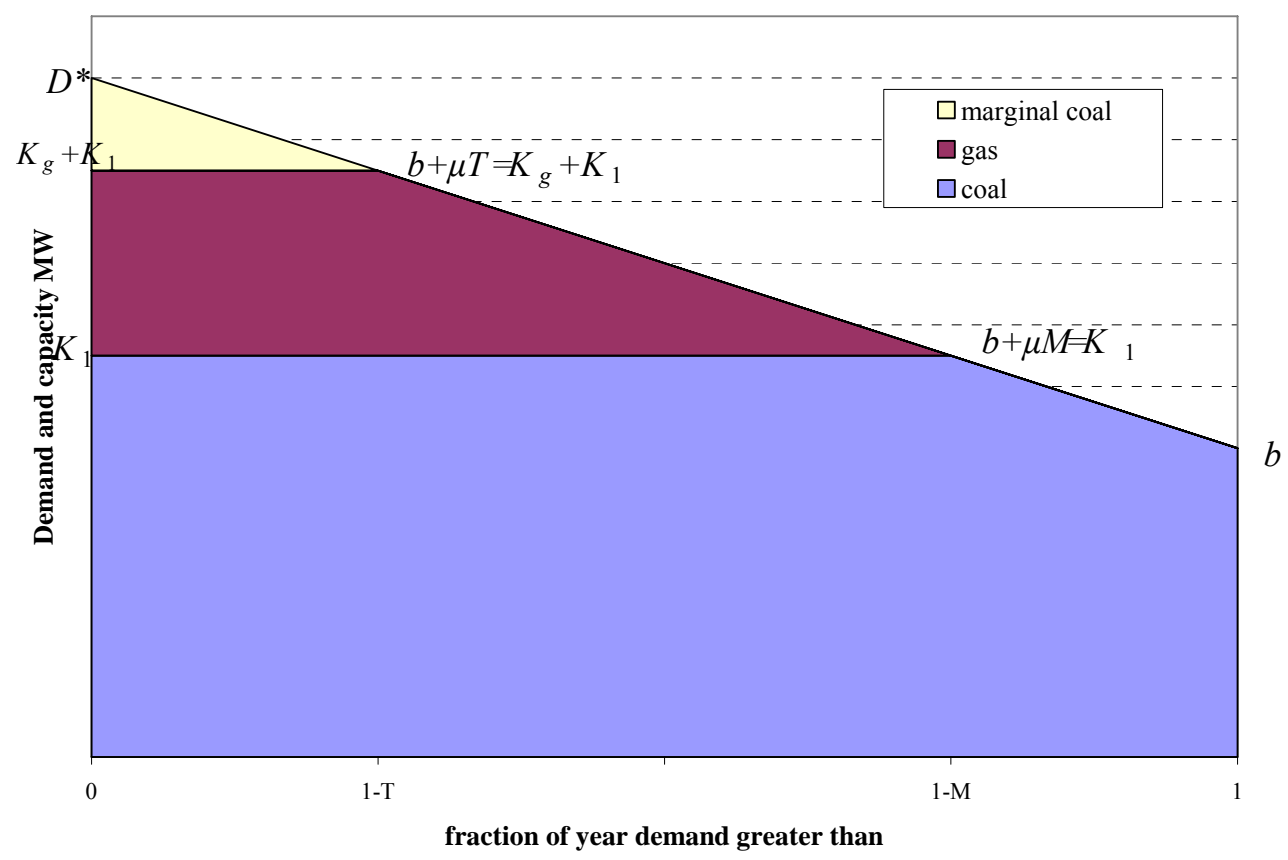

Figure A1 Gas entirely off base-load

At even higher prices of gas gas-fired generation might move down the merit order (i.e. run less and appear at the top of the load duration curve), but as before the links in the chain of reasoning between gas price, gas demand and the mitigating effect through the price of EUAs will continue (but with different numerical values). The volume of gas-fired generation will be

$$
Q_{g}=K_{g}\left(1-\frac{1}{2}(T+M)\right)=K_{g}\left(\frac{\mu+b-K_{1}-\frac{1}{2} K_{g}}{\mu}\right)
$$


As before, $d G / d g=\theta\left(d Q_{g} / d K_{1}\right) .\left(d K_{1} / d g\right)$. For the merit order shown in Figure A1 and from (A2), $d Q_{g} / d K_{1}=-K_{g} / \mu$, which has the same sign as, and is similar to, the merit order case of figure 5, where $d Q_{g} / d K_{1}=-\left(K_{1}+K_{g}-b\right) / \mu$. The effect on the ratio of gas demand elasticities remains $\left(d K_{1} / d g\right) /\left(\partial K_{1} / \partial g\right)$ and this is not affected by the form of $Q_{g}$, although the terms in (14) will need to be recomputed. Using the same techniques as before, $\partial E_{c} / \partial K_{1}=$ $8760 e_{c} h\left(K_{1}\right) K_{g} / \mu$, so $\partial E / \partial K_{1}=8760 K_{g} / \mu\left\{e_{c} h\left(K_{1}\right)-h_{g} e_{g}\right\}>0$. This is the same as (11) multiplied by $K_{g} / \mu T$. As the formula for $\partial K_{1} / \partial s$ is unchanged, the value of $\varphi$ is also multiplied by $K_{g} / \mu T$, which with the parameters of Table 1 is slightly less than 0.5 (although of course, the gas price would have to change, and that would also have an effect). In general one would expect the elasticity to be less affected by the ETS as gas became a smaller share of generation.

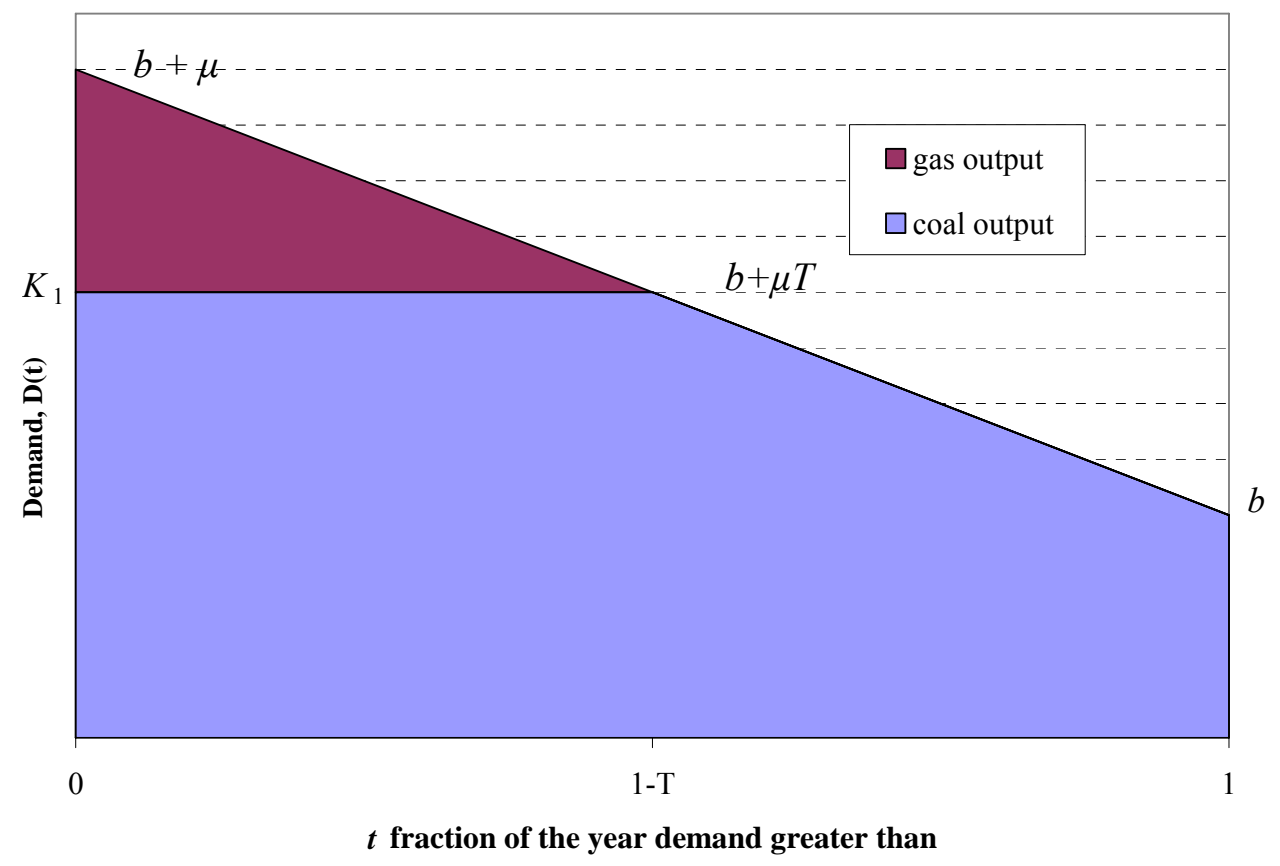

Figure A2 CCGT mid merit and peaking

The situation shown in figure A2 again has $K_{1}$ determined by (7) (assuming that the solution $\left.K_{1}{ }^{\prime \prime} K_{c}\right)$ but the amount of gas capacity actually needed is $\mu(1-T)$ " $K_{g}$ so that $T=\left(b-K_{1}\right) / \mu$. Gas-fired output is $Q_{g}=1 / 2 \mu(1-T)^{2}$ so that $d Q_{g} / d K_{1}=(1-T)$, which this time is positive. However, $\partial E / \partial K_{1}=8760(1-T)\left\{e_{c} h\left(K_{1}\right)-h_{g} e_{g}\right\}>0$, this time multiplying $\varphi$ by $(1-T) / T$. Qualitatively, the results do not change, although the changing gas prices needed to produce these configurations will affect the numerical results. 